\title{
Mechanisms of Stroke in Coronavirus Disease 2019
}

\author{
Victor Montalvan, ${ }^{\mathrm{a}}$ John De Toledo, ${ }^{\mathrm{a}}$ Kenneth Nugent ${ }^{\mathrm{b}}$ \\ aDepartment of Neurology, Texas Tech University Health Sciences Center, Lubbock, TX, USA \\ ${ }^{b}$ Division of Pulmonology and Critical Care, Department of Internal Medicine, Texas Tech University Health Sciences Center, School of Medicine, \\ Lubbock, TX, USA
}

\section{Dear Sir:}

Stroke was not a commonly reported complication with severe acute respiratory syndrome coronavirus 2 (SARS-CoV) virus infection that preceded the coronavirus disease 2019 (COVID-19) pandemic. Few reports described stroke due to large vessel occlusion in SARS infected patients. ${ }^{1}$ During the last few months, an increasing number of reports show COVID-19 patients developing stroke with several published attempts to explain this potential association. ${ }^{2-4}$ Whether the association is real or whether this is only an apparent fact that has been magnified by the much larger number of infected patients and the great scrutiny by a more diverse group of clinicians is an important question that needs answer.

In a recent observational study from China, 14 strokes out of 214 patients with COVID-19 were reported. Those patients with severe systemic presentation and cardiovascular risk factors were more likely to have acute cerebrovascular diseases. ${ }^{2}$ In another report, four elderly patients with multiple cardiovascular risk factors diagnosed with COVID-19 developed stroke. Large vessel disease (LVD) was documented as the mechanism of vascular damage in all of them. ${ }^{3}$ Other four COVID-19 patients aged between 45 and 77 years who developed stroke were reported, all of them with vascular risk factor including hypertension (HTN) and diabetes mellitus (DM). LVD was demonstrated in two of them and small vessel disease in the other two patients. ${ }^{5}$ Five cases of stroke in the context of COVID-19 were reported more recently. Three of these younger patients, had vascular risk factors, including DM, dyslipidemia, and HTN. LVD was also demonstrated in all of them, and all patients were treated with endovascular therapy. ${ }^{4}$

Coagulation abnormalities were also observed in patients with severe COVID-19. Endothelial injury due to direct viral at- tack can activate the coagulation system via exposure of tissue factor. This and a severe inflammatory reaction can result in an initial hypercoagulable state with elevated levels of D-dimer and fibrinogen, eventually disseminated intravascular coagulation (DIC). ${ }^{6}$ These coagulation changes could be the main mechanisms of ischemic stroke observed in some younger patients with less vascular risk factors., ${ }^{3,6}$

This apparent association of COVID-19 and stroke, however, might be due to the fact that both conditions share similar risk factors. A recent meta-analysis of eight studies from China, including 46,248 infected patients, showed that the most prevalent comorbidities were HTN (17\%) and DM (8\%), followed by cardiovascular diseases (5\%).7 Evidence also suggests that the severity of COVID-19 infection is directly related to the presence of HTN, DM, obesity, and elderly status that also increase the risk of developing stroke mainly from small vessel occlusion, LVD, and cardioembolism. ${ }^{4,5,7,8}$

In patients with COVID-19 and vascular risk factors, ${ }^{7,8}$ stroke may be triggered by complications of the critically ill settings, such as HTN, shock, arrhythmogenic cardiomyopathy, heart failure, and $\mathrm{DIC}_{1}^{3,4,8-10}$ that potentially contribute to hypoperfusion of brain parenchyma, and embolism leading to LVD. In an observational study of 138 hospitalized patients with COVID-19, shock was observed in 8.7\%, acute cardiac injury was present in $7.2 \%$, and arrhythmia occurred in $16.7 \% .{ }^{9}$ Another observational study of 191 patients in China with COVID-19 showed that 23\% were complicated with heart failure, 20\% had septic shock, 19\% had coagulopathy, and 17\% had acute cardiac injury. ${ }^{8}$ These factors provide additional risk to previously predisposed patients to develop an ischemic stroke in the context of COVID-19 infection.

LVD is being observed in multiple isolated reports of COVID-19 patients developing stroke and seems to be one of the main etiologies in this group of patients. ${ }^{3-5}$ However, there 
is circumstantial evidence suggesting that the cause of stroke in patients infected with COVID-19 is otherwise multifactorial. The list of mechanisms likely include SARS-CoV-2 induced coagulopathy, ${ }^{6}$ advanced arteriosclerosis, and critically ill patient complications, such as hypoperfusion and emboligenic cardiopathy. The presence of specific viral factors directly causing hypercoagulability, arteritis, and endothelial dysfunction, leading to ischemic stroke and the role of antithrombotic/anticoagulation therapy need to be clarified in further research.

\section{References}

1. Umapathi $T$, Kor AC, Venketasubramanian N, Lim CC, Pang $B C$, Yeo $T$, et al. Large artery ischaemic stroke in severe acute respiratory syndrome (SARS). J Neurol 2004;251:12271231.

2. Mao $L$, Jin $H$, Wang $M, H u Y$, Chen $S$, He $Q$, et al. Neurologic manifestations of hospitalized patients with coronavirus disease 2019 in Wuhan, China. JAMA Neurol 2020 Apr 10 [Epub]. https://doi.org/10.1001/jamaneurol.2020.1127.

3. Avula A, Nalleballe K, Narula N, Sapozhnikov S, Dandu V, Toom S, et al. COVID-19 presenting as stroke. Brain Behav Immun 2020 Apr 28 [Epub]. https://doi.org/10.1016/j.bbi.2020.04.077.

4. Oxley TJ, Mocco J, Majidi S, Kellner $C P$, Shoirah $H$, Singh IP, et al. Large-vessel stroke as a presenting feature of COVID-19 in the young. N Engl J Med 2020;382:e60.

5. Tunç $A$, Ünlübaş Y, Alemdar M, Akyüz E. Coexistence of COVID-19 and acute ischemic stroke report of four cases. J Clin Neurosci 2020 May 6 [Epub]. https://doi.org/10.1016/j.jocn.2020.05.018.

6. Tang N, Li D, Wang X, Sun Z. Abnormal coagulation parame- ters are associated with poor prognosis in patients with novel coronavirus pneumonia. J Thromb Haemost 2020;18:844847.

7. Yang J, Zheng Y, Gou X, Pu K, Chen Z, Guo Q, et al. Prevalence of comorbidities in the novel Wuhan coronavirus (COVID-19) infection: a systematic review and meta-analysis. Int J Infect Dis 2020 Mar 17 [Epub]. https://doi.org/10.1016/ J.IJID.2020.03.017.

8. Zhou F, Yu T, Du R, Fan G, Liu Y, Liu Z, et al. Clinical course and risk factors for mortality of adult inpatients with COVID-19 in Wuhan, China: a retrospective cohort study. Lancet 2020;395:1054-1062.

9. Wang D, Hu B, Hu C, Zhu F, Liu X, Zhang J, et al. Clinical characteristics of 138 hospitalized patients with 2019 novel coronavirus-infected pneumonia in Wuhan, China. JAMA 2020; 323:1061-1069.

10. Chen N, Zhou M, Dong X, Qu J, Gong F, Han Y, et al. Epidemiological and clinical characteristics of 99 cases of 2019 novel coronavirus pneumonia in Wuhan, China: a descriptive study. Lancet 2020;395:507-513.

Correspondence: Victor Montalvan

Department of Neurology, Texas Tech University Health Sciences Center, 3601 4th Street, RM 3A105 (located in TUHSC building), Lubbock, TX 79430, USA Tel: +1-806-743-2391

Fax: +1-806-743-5687

E-mail: victor.montalvan@ttuhsc.edu

Received: May 15, 2020

Revised: May 15, 2020

Accepted: May 15, 2020

The authors have no financial conflicts of interest. 
